\title{
Erratum: Castellví, M. et al. Pharmacological Modulation of SAMHD1 Activity by CDK4/6 Inhibitors Improves Anticancer Therapy. Cancers $2020,12,713$
}

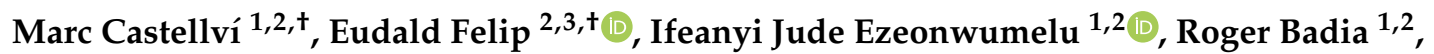 \\ Edurne Garcia-Vidal 1,2, Maria Pujantell 1,2 (D), Lucía Gutiérrez-Chamorro 1,2 , Iris Teruel 2,3 (D), \\ Anna Martínez-Cardús 2,3 (D), Bonaventura Clotet 1,2, Eva Riveira-Muñoz 1,2 , Mireia Margelí ${ }^{2,3}$, \\ José A. Esté 1,4 (iD) and Ester Ballana 1,2,* \\ 1 IrsiCaixa AIDS Research Institute, Badalona, 08916 Catalonia, Spain; mcnadal89@gmail.com (M.C.); \\ iezeonwumelu@irsicaixa.es (I.J.E.); rbadia@irsicaixa.es (R.B.); egvidal@irsicaixa.es (E.G.-V.); \\ mpujantell@irsicaixa.es (M.P.); lgutierrez@irsicaixa.es (L.G.-C.); bclotet@irsicaixa.es (B.C.); \\ eriveira@irsicaixa.es (E.R.-M.); jaeste@cienciatraducida.com (J.A.E.) \\ 2 Health Research Institute Germans Trias i Pujol (IGTP), Hospital Germans Trias i Pujol, \\ Universitat Autònoma de Barcelona, 08916 Badalona, Spain; efelip@irsicaixa.es (E.F.); \\ iteruel@iconcologia.net (I.T.); amartinezc@igtp.cat (A.M.-C.); mmargeli@iconcologia.net (M.M.) \\ 3 Institut Català d'Oncologia, Badalona, 08916 Catalonia, Spain \\ 4 Cienciatraducida, 08391 Barcelona, Spain \\ * Correspondence: eballana@irsicaixa.es \\ + Theses authors contributed equally this work.
}

Received: 5 June 2020; Accepted: 8 June 2020; Published: 29 June 2020

The authors wish you make the following corrections to this paper [1].

One contributor's name was missing in the original version of the authorship. The original version of the authorship is:

Marc Castellví 1,2,t, Eudald Felip 2,3,t, Ifeanyi Jude Ezeonwumelu 1,2, Roger Badia 1,2, Edurne Garcia-Vidal 1,2, Maria Pujantell 1,2, Lucía Gutiérrez-Chamorro 1,2, Iris Teruel 2,3, Anna Martínez-Cardús 2,3, Bonaventura Clotet 1,2, Eva Riveira-Muñoz 1,2, Mireia Margelí 2,3 and Ester Ballana 1,2,*

and should be replaced with:

Marc Castellví 1,2,†, Eudald Felip 2,3,t, Ifeanyi Jude Ezeonwumelu 1,2, Roger Badia 1,2, Edurne Garcia-Vidal 1,2, Maria Pujantell 1,2, Lucía Gutiérrez-Chamorro 1,2, Iris Teruel 2,3, Anna Martínez-Cardús 2,3, Bonaventura Clotet 1,2, Eva Riveira-Muñoz 1,2, Mireia Margelí 2,3, José A. Esté 1,4, and Ester Ballana 1,2,*

The updated "Author Contributions" should be

Author Contributions: Conceptualization, J.A.E., E.R.-M., M.M. and E.B.; Formal analysis, M.M., J.A.E. and E.B.; Investigation, M.C., E.F., I.J.E., R.B., E.G.-V., M.P. and L.G.-C.; Methodology, I.T. and A.M.-C.; Supervision, B.C. and J.A.E.; Writing-original draft, E.B. and J.A.E.; Writing-review \& editing, E.R.-M. and E.B. All authors have read and agreed to the published version of the manuscript. 


\section{Reference}

1. Castellví, M.; Felip, E.; Ezeonwumelu, I.J.; Badia, R.; Garcia-Vidal, E.; Pujantell, M.; Gutiérrez-Chamorro, L.; Teruel, I.; Martínez-Cardús, A.; Clotet, B.; et al. Pharmacological Modulation of SAMHD1 Activity by CDK4/6 Inhibitors Improves Anticancer Therapy. Cancers 2020, 12, 713. [CrossRef] 